\title{
The renal glomerulus in hypoxic cor pulmonale
}

\author{
JOHN L CAMPBELL, PETER MA CALVERLEY, DAVID LAMB, DAVID C FLENLEY \\ From the University Departments of Pathology, Medicine, and Respiratory Medicine, Edinburgh
}

\begin{abstract}
We measured the mean capillary tuft area by a custom-built semi-automatic technique in postmortem sections from the kidneys of 16 patients with "blue and bloated" chronic bronchitis and emphysema and in seven patients of similar age who were free of respiratory and renal disease at death. Nine bronchitic patients had received domiciliary oxygen treatment while seven had not. The mean glomerular tuft area in these treated bronchitic patients $\left(14200 \mu \mathrm{m}^{2}\right)$ was not significantly different from that of the untreated patients $\left(16900 \mu \mathrm{m}^{2}\right)$ but the tuft area in the bronchitic subjects was significantly larger than that of the non-bronchitic controls $\left(12100 \mu \mathrm{m}^{2}, \mathrm{p}\right.$ $<0.02)$. There was no reduction in glomerular cellularity to suggest passive venous distension, and glomerular size was not correlated with clinical or pathological indices of cor pulmonale (including red cell mass). The arterial oxygen tension $\left(\mathrm{Po}_{2}\right)$, however, was correlated with glomerular size $(r=0.68, \mathrm{p}<0.01)$ if allowance was made for the higher $\mathrm{Po}_{2}$ of the patients receiving oxygen. The percentage of glomeruli with an identifiable juxtaglomerular apparatus also increased with increasing glomerular size. These structural changes in the kidneys of patients with severe chronic bronchitis and ephysema may reflect changes in renal salt and water handling that are potentially reversible by oxygen treatment.
\end{abstract}

Episodes of peripheral oedema often complicate hypoxic chronic bronchitis and emphysema and several mechanisms have been postulated to explain them.' Various pathological changes have been described in the kidneys of such patients, including glomerular enlargement, capillary tuft hypercellularity, and tubular changes such as enlargement and vacuolation. ${ }^{23}$ Similar pathological changes have also been observed in patients who are hypoxic from cyanotic congenital heart disease ${ }^{4}$ or are developing right heart failure owing to chronic rheumatic heart disease. ${ }^{5}$

Glomerular enlargement in cor pulmonale was first observed by Ellis in 1961 but little attention has been paid to possible aetiological factors. The observation that total renal mass increases in patients with cor pulmonale has also been disputed by workers studying related cardiac problems. ${ }^{56} \mathrm{We}$ have studied a relatively homogeneous group of patients who suffered from hypoxic cor pulmonale secondary to severe chronic bronchitis and emphysema, and have attempted to determine which renal lesions were specific to these patients and to identify any associated pathogenic factors.

Address for reprint requests: Dr PMA Calverley, Chest Unit, City Hospital, Edinburgh EH10 5SB.

\section{Material and methods}

We studied the postmortem kidneys of 16 patients who had suffered from chronic bronchitis and emphysema and compared them with kidneys from seven control subjects free from respiratory disease. The bronchitic patients had all been participants in the Medical Research Council (MRC) trial of long-term domiciliary oxygen treatment, ${ }^{7}$ nine of the patients having been treated with 2 litres of oxygen a minute for 15 hours a day for 10-87 months before death (mean 36 months). The remaining patients had similar medical treatment but did not receive domiciliary oxygen. All the bronchitic patients had at least one documented episode of cardiac failure with ankle oedema and severe irreversible airways obstruction, persistent arterial hypoxaemia with carbon dioxide retention, secondary polycythaemia, and mild pulmonary hypertension (table 1 ). None suffered from fibrotic or infiltratative lung disease, systemic hypertension, proved coronary artery disease, or other life-threatening illness. At necropsy cor pulmonale was confirmed on the basis of right:left heart weight ratios. ${ }^{89}$

The non-bronchitic controls were selected retrospectively from the necropsy files of patients from 50 to 80 years of age who had recently died and who 
Table 1 Physiological variables in patients with chronic bronchitis and emphysema measured in the year before death (values as mean $\pm S D$ )

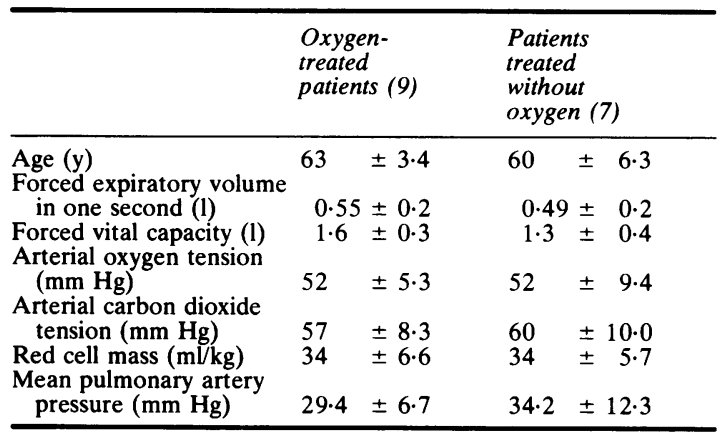

were not known to have diseases affecting glomerular size-for example, diabetes mellitus, chronic congestive cardiac failure, rheumatic heart disease, or lung disease - or to have primary renal diseasefor example, renal carcinoma or glomerulonephritis.

The glomeruli were examined on paraffin-waxembedded blocks of tissue which displayed the renal capsule and corticomedullary boundary. These blocks had previously been fixed in $10 \%$ formalin before being cut at a thickness of $3 \mu \mathrm{m}$ and stained with haematoxylin and eosin. The following variables were investigated:

1 Glomerular size Application of Dunnill's method of constructing summation-average graph $\mathbf{s}^{10}$ to renal glomerular tuft area showed that the measurement of mean capillary tuft area in $\mathbf{7 0}$ glomeruli from one randomly obtained tissue section gave a reliable indication of the glomerular size within the kidney from which the section was derived (given the absence of focal renal pathology-for example, visible scarring).

Glomerular size was measured with a semiautomatic measuring system linked to a desk-top computer (Graphic Data Systems GDSI 4041). The outline of the capillary tuft was accurately circumscribed with a pinpoint of light reflected from a cursor into the optics of a light microscope (Leitz SM LUX $\times 317 \cdot 5$ ). Impulses generated by the cursor on a platen provided raw data for the mathematical calculation of the capillary tuft area by the computer. Glomeruli in the section were sampled along marker lines drawn on the coverslip overlying the section. These lines crossed capsule and corticomedullary boundary vertically, thus allowing for any differences in size between subcapsular and juxtamedullary glomeruli. The glomerular size in different groups of subjects was compared on the basis of the mean capillary tuft area for that sample.
2 Percentage of renal cortical area occupied by glomeruli This was assessed using a modification of the procedure of Hutchins and Kutchemeshgi. ${ }^{11}$ Three hundred and sixty points were assessed (point counting) as overlying glomerular or nonglomerular renal cortical tissue, the glomerulus being considered as the area bounded by the Bowman's capsule. The percentage of renal cortical area occuped by the glomeruli was determined from the number of points overlying glomerular tissue expressed as a percentage of the total number of points counted.

3 Cellularity of the capillary tuft Tuft cellularity was assessed in 10 glomeruli from each tissue section examined. The total number of nuclei visible within the calculated tuft area was determined and expressed as the number of nuclei per square millimetre of tuft area.

4 Tuft renal mass The data on renal mass were obtained from fresh necropsy material. All the necropsies were performed by one of two experienced pathologists, who weighed the fresh renal tissue after careful removal of perinephric fat. Renal mass was expressed as grams per square metre of body surface area, which was determined from measurements in life (with the use of standard nomograms. ${ }^{12}$ In three of the non-bronchitic control subjects data on surface area were not available and a figure of $1.73 \mathrm{~m}^{2}$ was assumed.

In all the bronchitic subjects measurements of $\mathrm{FEV}_{1}$, FVC, and arterial blood gas tensions during the breathing of air or oxygen were available from twomonthly clinic attendances.

The red cell mass (measured by injection of chromium-51-labelled autologous red cells) and pulmonary artery pressure and cardiac output measurements, made with the subjects supine and breathing air, were available from data obtained at entry to the MRC trial and annually thereafter. The bronchitic subjects were initially subdivided into those treated with domiciliary oxygen and those who acted as untreated controls; but subsequently the whole group was separated into those with normal glomerular size - that is, glomeruli lying within the upper $95 \%$ quartile of the non-bronchitic control sample (less than $14600 \mu^{2}$ ) and those with abnormally large glomeruli that were outside these limits.

The percentage of glomeruli displaying visible juxtaglomerular cells was also measured in each subject. On each tissue section examined $(\times 125)$, a large number of glomeruli (mean $174 \pm 10$ ) were assessed as having or not having visible juxtaglomerular cells. 
Table 2 Pathological measurements in patients with chronic bronchitis and emphysema and non-bronchitic controls (values as mean $\pm S D$ )

\begin{tabular}{|c|c|c|c|}
\hline & \multirow{2}{*}{$\begin{array}{l}\text { Non-bronchitic } \\
\text { patients (7) }\end{array}$} & \multicolumn{2}{|c|}{ Bronchitic patients } \\
\hline & & $\begin{array}{l}\text { Normal-sized } \\
\text { glomeruli (6) }\end{array}$ & $\begin{array}{l}\text { Large glomueruli } \\
\text { (10) }\end{array}$ \\
\hline \multirow{2}{*}{$\begin{array}{l}\text { Glomerular tuft area }\left(\mu \mathrm{m}^{2}\right) \\
\text { Cellularity of tuft (nuclei/mm² tuft area) } \\
\text { Total renal mass (g) } \\
\text { Glomeruli with visible juxtaglomerular } \\
\text { apparatus (\%) }\end{array}$} & $\begin{aligned} 12106 & \pm 471 \\
6300 & \pm 1350 \\
330 & \pm 27\end{aligned}$ & $\begin{aligned} 10883 & \pm 1552 \\
7200 & \pm 1670 \\
240 & \pm 13\end{aligned}$ & $\begin{aligned} 18022 & \pm 2594 \\
5980 & \pm 230 \\
318 & \pm 23\end{aligned}$ \\
\hline & $13 \cdot 3 \pm 7 \cdot 0$ & $14 \cdot 2 \pm 7 \cdot 0$ & $20.9 \pm 8.0$ \\
\hline
\end{tabular}

In all pathological measurements throughout the study the observer was unaware of the disease or treatment group to which the subject belonged at the time when the pathological measurements were made.

\section{Results}

Non-bronchitic control subjects had a mean glomerular size of $12106 \pm 471 \mu \mathrm{m}^{2}$, which was significantly smaller than that of either group of bronchitics (mean glomerular size in oxygen-treated bronchitics $14178 \pm 1306 \mu \mathrm{m}^{2}$ and in untreated bronchitics $\left.16846 \pm 1640 \mu \mathrm{m}^{2}\right)(\mathrm{p}<0.02)$. There was no significant difference in glomerular size between the two groups of bronchitic patients and for this reason the two samples were pooled for subse-

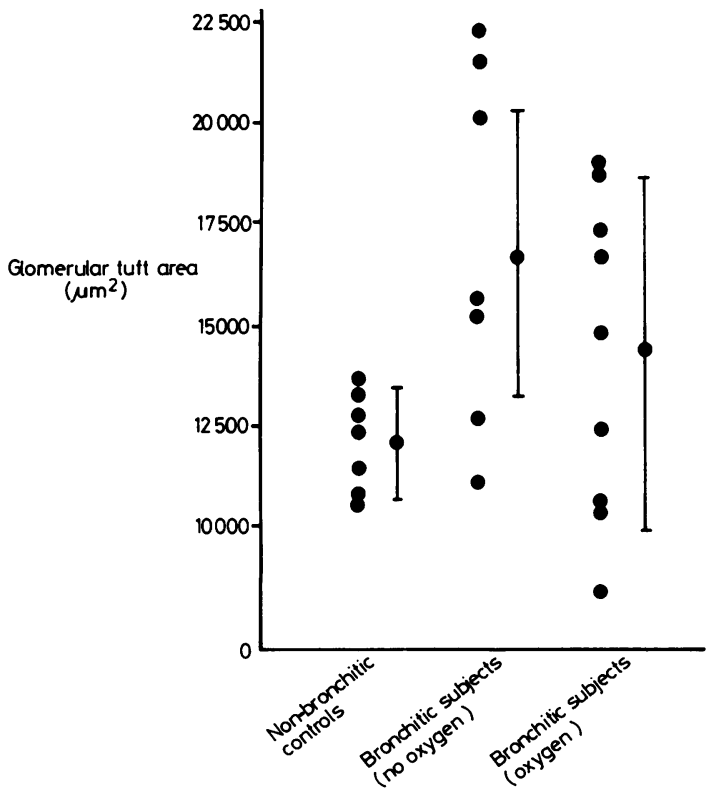

Fig 1 Glomerular tuft area in bronchitic and non-bronchitic patients (values as mean $\pm S D$ ). quent analysis (fig 1). Moreover, bronchitic subjects showed a greater variation in glomerular size than the non-bronchitic controls, some having a mean glomerular size that fell within normal limits and others having enlarged glomeruli (fig 1).

The kidneys of the bronchitic patients with normal-sized glomeruli resembled those of the non-bronchitic controls in several ways. A similar percentage of the renal cortical area was occupied by glomeruli in both groups $-6.8 \pm 1.9 \%$ and $6.7 \pm$ $1.1 \%$ respectively. The cellularity of the capillary tuft was also similar in the two groups (table 2). The mean total renal mass of $240 \pm 13 \mathrm{~g} / \mathrm{mm}^{2}$ was, however, significantly less in the bronchitic patients than in the non-bronchitic group (table 2). In contrast, the bronchitic subjects with abnormally large glomeruli had a total renal mass similar to that in the

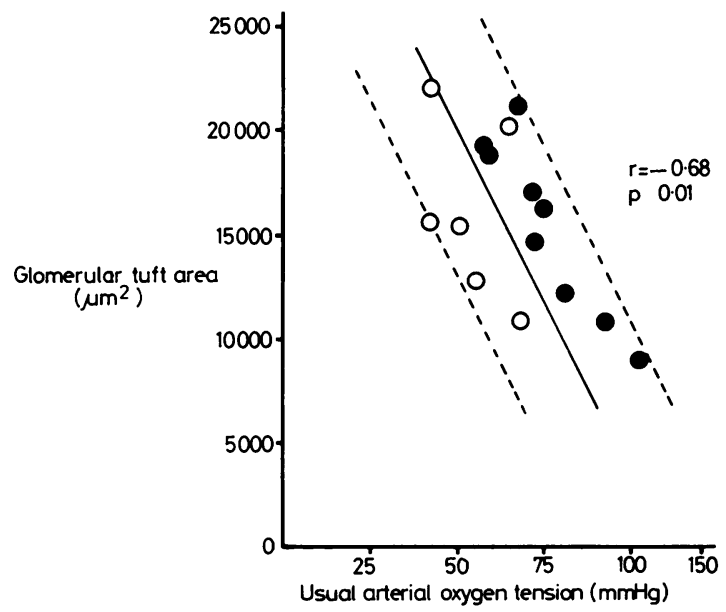

Fig 2 Relation between usual arterial oxygen tension and glomerular tuft area in chronic bronchitis and emphysema. - - oxygen-treated patients; $\mathrm{O}-$ control bronchitic patients. Conversion: Conventional to SI units-Arterial oxygen tension: $1 \mathrm{~mm} \mathrm{Hg}=0.13 \mathrm{kPa}$. 
non-bronchitic controls $\left(181 \pm 40 \mathrm{~g} / \mathrm{mm}^{2}\right)$ and in these subjects the glomeruli occupied $8 \cdot 2 \pm 1.3 \%$ of the renal cortex. The cellularity of the capillary tuft per square millimetre was similar in all three groups.

There was no relation between any of the physiological variables measured initially in the bronchitic patients and the size of their glomeruli, nor was any relation found between the severity of airways obstruction or the degree of carbon dioxide retention or of pulmonary hypertension during the last year of life and the size of the glomeruli. Moreover, the red cell mass measurements in the year before death did not correlate with glomerular size or with total renal mass. When allowance is made, however, for the fact that the oxygen-treated patient would have a higher daytime arterial oxygen tension on treatment than the untreated controls, and the values for arterial oxygen tension during the breathing of 2 litres of oxygen a minute are substituted for $\mathrm{PaO}_{2}$ values during the breathing of air, then a highly significant relationship emerges between decrease in arterial oxygen tension and increase in glomerular size $(r=-0.68$, $\mathrm{p}<0.01$; fig 2).

\section{Discussion}

The development of cor pulmonale in a patient with chronic bronchitis and emphysema is associated with a poor prognosis, ${ }^{13}$ which may be improved by long-term domiciliary oxygen treatment. ${ }^{714}$ In the past pathological attention in this condition has focused on the changes occurring within the pulmonary circulation; ${ }^{15}$ but a renally mediated increase in total body sodium is thought to occur in most oedematous states, ${ }^{16}$ although this has been disputed in the case of cor pulmonale. ${ }^{17}$ We have confirmed Ellis's original observation that an increase in glomerular size may occur in cor pulmonale by studying a relatively homogenous group of patients who did not die in overt congestive heart failure. A continuum of glomerular size is seen between those with tuft areas within our normal range, whose glomeruli were indistinguishable from those of the control patients, and those patients with larger glomeruli, which were structurally different from normal.

Previous authors have speculated that this glomerular enlargement may reflect work hypertrophy within the kidneys secondary to carbon dioxide retention and increased hydrogen ion secretion ${ }^{2}$ or, alternatively, that it may be due to an increase in the red cell mass, producing an opening up of glomerular capillaries. ${ }^{3}$ We were able to compare the pathological findings in our patients with a large number of physiological variables measured in the year before the patient's death and we found no relation between either the arterial carbon dioxide tension or the red cell mass and the size of the glomeruli. There was, however, a significant relation between glomerular size and the day-time arterial oxygen tension. Nine of our patients received domiciliary oxygen treatment for at least six months before death and in this group there was no relation between the size of the glomeruli and the arterial oxygen tension during the breathing of air. Only when we substituted the oxygen tension while the patient was breathing 2 litres of oxygen a minutethat is, the oxygen tension during treatment for at least 15 hours a day-did a significant relation emerge, implying that domiciliary oxygen treatment probably reduces glomerular size.

Renal blood flow falls in patients with hypoxic chronic bronchitis and emphysema after exposure to $100 \%$ oxygen. $^{1819}$ If, however, the arterial oxygen tension of the patients already hypoxic from chronic bronchitis and emphysema falls below $30 \mathrm{~mm} \mathrm{Hg}$ $(4 \mathrm{kPa})$ glomerular filtration rate falls and sodium retention occurs. ${ }^{19}$ Levels of severe hypoxia such as these were found during sleep in several of the patients in the present study. ${ }^{20}$ The relation between oxygen tension and glomerular size provides a pathological counterpart of that between renal blood flow and hypoxia and may represent compensatory hypertrophy in glomeruli repeatedly exposed to low oxygen tension and temporarily increased perfusion.

The juxtaglomerular apparatus was observed to undergo a disproportionate increase in size in relation to the glomerular enlargement seen in the bronchitic patients. Further work is required to determine whether this histopathological observation relates directly to abnormalities of either the polycythaemia or the fluid retention seen in these patients.

Campbell and colleagues have postulated that changes in the body tissue mass lead to a release of $\vec{D}$ intracellular water and play an important part in the genesis of cor pulmonale. ${ }^{17}$ The structural changes we have observed in the glomeruli and juxtaglomerular apparatus in patients with cor pulmonale and the relation of the glomerular changes to the severity of hypoxaemia in life suggest that changes in the renal handling of sodium and water in $O$ response to changes in the arterial oxygen tension may be the principal abnormality leading to oedema in chronic bronchitis and emphysema.

We wish to thank Dr D Thomson for much helpful criticism and advice on the renal pathology. 


\section{References}

${ }^{1}$ Campbell EJM, Short DS. The cause of oedema in cor pulmonale. Lancet 1960;1:1184-6.

${ }^{2}$ Ellis PA. Renal enlargement in chronic cor pulmonale. J Clin Path 1961;14:552-6.

${ }^{3}$ Ishikawa S, Bowden GH, Wyatt JP. The glomerular capillary bed in chronic pulmonary emphysema. Am Rev Respir Dis 1969;100:95-8.

${ }^{4}$ Spear GS. The glomerulus in cyanotic congenital heart disease and primary pulmonary hypertension. Nephron 1964; i:238-48.

${ }^{5}$ Rosenmann E, Dwarka L, Boss JH. Proliferative glomerulopathy in rheumatic heart disease and chronic lung disease. Am J Med Sci 1972;264:213-23.

- Bauer WC, Rosenberg BF. A quantitative study of glomerular enlargement in children with tetralogy of Fallot. Am J Path 1960;37:695-708.

${ }^{7}$ Report of Medical Research Council working party. Long term domiciliary oxygen therapy in chronic hypoxic cor pulmonale complicating chronic bronchitis and emphysema. Lancet 1981;i:681-5.

${ }^{8}$ Fulton RM, Hutchinson EC, Jones AH. Ventricular weight in cardiac hypertrophy. $\mathrm{Br}$ Heart $\mathrm{J}$ 1952;14:413-20.

${ }^{9}$ Lamb D. Heart weight and assessment of ventricular hypertrophy. In: Dyke SC, ed. Recent advances in clinical pathology. Edinburgh: Churchill Livingstone, 1973:133-48.

${ }^{10}$ Dunnill MS. Evaluation of a simple method of sampling the lung for quantitative histological analysis. Thorax 1964;19:443-8.

${ }^{11}$ Hutchins GM. Kutchemeshgi AD. Renal glomerular enlargement in chronic passive congestion. Johns Hopkins Med J 1973;132:292-300.

${ }^{12}$ Documenta Geigy scientific tables. 7th ed. Basle: JR Geigy, 1973.

${ }^{13}$ Renzetti AD, McClement JH, Litt BD. The Veterans Administration co-operative study of pulmonary function. III: Mortality in relation to respiratory function in chronic obstructive lung disease. Am J Med 1966;41:115-29.

${ }^{14}$ Nocturnal Oxygen Therapy Trial Group. Continuous or nocturnal oxygen therapy in hypoxaemic chronic obstructive lung disease. Ann Intern Med 1980; 93:391-8.

is Fishman AP. Chronic cor pulmonale. Am Rev Respir Dis 1976;114:775-94.

${ }^{16}$ Farber SJ, Soberman RJ. Total body water and total exchangeable sodium in oedematous states due to cardiac, renal or hepatic disease. J Clin Invest 1956;35:779-91.

${ }^{17}$ Campbell RHA, Brand HL, Cox JR, Howard P. Body weight and body water in chronic cor pulmonale. Clin Sci Mol Med 1975;49:323-5.

${ }^{18}$ Aber GM, Harris AM, Bishop JM. The effect of acute changes in inspired oxygen concentration on cardiac, respiratory and renal function in patients with chronic obstructive airways disease. Clin Sci 1964;26:133-43.

${ }^{19}$ Kilburn KH, Dowell AR. Renal function in respiratory failure. Effects of hypoxia, hyperoxia and hypercapnia. Arch Intern Med 1971;127:754-62.

${ }^{20}$ Douglas NJ, Calverley PMA, Leggett RJE, Brash BH, Flenley DC, Brezinova V. Transient hypoxaemia during sleep in chronic bronchitis and emphysema. Lancet 1979;i:1-4. 